\title{
De maio de 1968 \\ a junho de 2013
}

José Eduardo Faria*

Não estrague sua podridão, diziam os estudantes parisienses nas manifestações de protesto de maio de 1968. Sejamos realistas: peçamos o impossível, afirmavam em coro. É proibido proibir, repetiam os estudantes brasileiros, traduzindo as palavras de ordem de seus colegas franceses. Aquele foi um momento de paixão e ação, que desencadeou um sem número de tentativas de interpretação sociológica, política e filosófica dos acontecimentos. Algumas análises foram argutas, porém incompletas. Outras, açodadas e marcadas pelo romantismo e por enviesamentos ideológicos ou doutrinários. De certo modo, o mesmo vem ocorrendo com as manifestações de protesto de junho de 2013, no Brasil. Palavras de ordem politicamente corretas têm sido invocadas para justificar um rol de reivindicações difusas, nem sempre coerentes e realistas - várias delas secundadas por truculência e explosões de vandalismo. Qual é a efetiva motivação desses manifestantes, além da pretensão de "reconhecimento de direitos?"

As manifestações de protesto ocorridas em maio de 1968, na França, tiveram o peso de uma série de fatores, catalizando ressentimentos e unificando reivindicações -muitas delas contraditórias- até eclodir sob a forma de uma revolta marcada por muita violência. No plano econômico, por exemplo, vivia-se o final de um ciclo de bem sucedidas políticas de pleno emprego, de ganhos reais de salários e de afirmação dos direitos sociais, iniciado no pós-guerra, e que propiciou um crescimento excepcional, sem precedentes na história. No plano político europeu, aquele foi o ano em que os soviéticos invadiram a então Tcheco-Eslováquia, liquidando, com blindados, a tentativa de afirmação de um "socialismo com rosto humano" - a chamada primavera de Praga. No plano político interno francês, pipocavam críticas a um Estado centralizador apoiado em um conservadorismo

* Doutor em Direito pela Universidade de São Paulo. Professor titular do Departamento de Filosofia e Teoria Geral do Direito, da Faculdade de Direito da Universidade de São Paulo e da Fundação Getúlio Vargas. 
social e cultural extremos. E, no plano acadêmico, emergiu uma profunda crise quanto à validade da ciência e a crença no progresso material decorrente de suas descobertas, levando a acirrados conflitos na redefinição de fins e funções no âmbito da Universidade e provocando com isso impasses sem precedentes entre professores e alunos. Orientada pelo pragmatismo, diziam os estudantes, a Universidade estava voltada apenas para a tarefa de produzir técnicos destinados a cumprir papéis específicos -limitados por sua própria especialização- no âmbito de uma sociedade de consumo e de um universo de empresas, mercados e dinheiro.

A primavera francesa de 1968 foi assim, também, um período explosivo de lutas contra o padrão fabril então vigente e sua lógica de produção massificada. A condição do consumidor - então visto como simples receptor passivo de mensagens - foi posta em xeque pela democratização da tomada da palavra e pela inovação das linguagens, abrindo caminho para uma nova relação entre ação e vida. A luta do operariado contra o fordismo - o trabalho repetitivo, monótono, alienado e alienante- teve como contraponto a recusa dos estudantes parisienses de reproduzir socialmente esse modelo de produção, baseado na distinção entre execução manual e concepção intelectual, afirmaram Negi e Cocco, chamando atenção para o advento de palavras de ordem surgidas nas fábricas e centro acadêmicos - palavras essas que, por meio da ironia e do escárnio frente ao poder- fugiam da lógica binária da política tradicional ${ }^{1}$. A primavera francesa de 1968 foi, igualmente, um período forte contestação intelectual e cultural, que acabou se expandindo e enfraquecendo os dispositivos disciplinares vigentes desde o término da $2^{a}$ guerra mundial. Com suas barricadas, passeatas e comícios, os universitários parisienses lançaram-se contra a política tradicional, contra as instituições governamentais e contra a ordem burguesa. Apoiados pelos segmentos mais jovens do operariado, que recusavam as determinações das lideranças stradicionais da Confederação Geral do Trabalho (CGT), do Partido Comunista e do Partido Socialista, os estudantes parisienses deflagraram a maior greve geral ocorrida até então na história trabalhista francesa. E ao interromper o sistema de transportes públicos e o fornecimento de água, luz e gás das grandes cidades, converteram Paris numa espécie de território livre e pararam o país durante três semanas, espalhando pelo resto do mundo uma onda de protestos, no sentido romântico de uma retomada dos impulsos morais que as gerações anteriores teriam deixado perecer.

Panfletos distribuídos nas imediações da Place de la Sorbonne, do Boulevard Saint Michel e das ruas Saint Jacques, Cujas, Soufflot, Gay-Lussac e D'Ulm classificavam a Universidade como "asilo de loucos". Outros panfletos lembravam que os estudantes franceses encontravam apenas miséria nas salas de aula. "Miséria intelectual, em cursos sobrecarregados, num ensino arcaico e meticulosamente seletivo, avesso a toda novidade, dedicando-se a reproduzir, em suas formas e conteúdo, a hierarquia social e os valores da submissão, confundindo neutralidade com mediocridade. Miséria intelectual ligada a esse preceito prático e difundido por toda a parte no campus, segundo qual o prazer 
era para mais tarde, quando o estudante fosse 'grande' e tivesse uma profissão. Miséria moral, pois o que lhe era oferecido como recompensa suprema, salvo o caso de uma sorte excepcional, era integrar-se na engrenagem azeitada de uma sociedade bem organizada segundo o princípio do rendimento assalariado e da segurança a qualquer preço" - resumiu um dos mais argutos analistas da época, o filósofo político e historiador da filosofia François Chatelet ${ }^{2}$. "Se nossa situação nos conduz à violência", dizia um dos panfletos mais ilustrativos, "é porque a sociedade toda nos violenta. Recusamos a violência da 'felicidade' feita a todos - essa felicidade escandalosa das horas extras, da barganha de nossa força de trabalho, de nossa força vital, trocada apor alguns brinquedinhos em preto e branco ou em cores, que só servem para depois nos sujeitarem melhor, privandonos de nossa humanidade".

A teoria deveria nascer da ação e da experiência, em vez de precedê-las - diziam os principais líderes das manifestações estudantis de 1968, como Daniel Cohn-Bendit, Jacques Sauvageot, Alain Geismar e Alain Krivine, desqualificando partidos políticos, lideranças sindicais tradicionais e dirigentes governamentais, prometendo "arrancar a máscara da hipocrisia da face do inimigo" e asseverando que o movimento estudantil não pretendia "conquistar o poder, mas transformálo". Todavia, na medida em que não tinham um programa de ação nem ofereciam alternativas claras, minimamente satisfatórias e factíveis, as lideranças estudantis foram obrigadas a enfrentar o desafio de manter e fomentar o protesto de qualquer modo, o protesto enquanto protesto, dando tempo ao tempo até que novas causas pudessem ser invocadas e novas proposições fossem apresentadas. Como lembrou Hannah Arendt, ao analisar aqueles acontecimentos, as instituições universitárias somente poderiam permanecer como base de poder dos estudantes, estimulando suas manifestações, enquanto tivessem "a consciência ou lucidez de não serrar o galho em que estavam sentados”, não se deixando levar nem pela radicalização nem pela violência. ${ }^{3}$

No Brasil, as ações e os protestos estudantis de 1968 -como a marcha dos 100 mil no Rio de Janeiro, a "batalha da rua Maria Antonia" em São Paulo e a realização do Congresso da União Nacional dos Estudantes, em Ibiúnaocorreram num país submetido a uma ditadura militar e ao mais inepto dos governos desse ciclo. Contudo, o que começou como uma iniciativa crítica e provocadora, por meio de passeatas e ocupações de dependências universitárias em quase todo o país, oito meses depois culminou no fatídico Ato Institucional $n^{\circ} 5$, editado em 13 de dezembro, levando a um período sombrio de dissolução das garantias individuais e afronta das liberdades públicas. Na França, depois um surto de prestígio nos meses subsequentes aos protestos de maio, o quase octogenário presidente Charles de Gaulle deixou de ser o homem providencial para transformar-se num dirigente alquebrado, lento na decisão e inábil ou desastrado na forma de agir. Depois de ter mandado reprimir com violência as manifestações parisienses, o que acabou convertendo os protestos estudantis em insurreição generalizada nas grandes cidades francesas, o general de Gaulle venceu o plebiscito no qual se comprometera a renunciar caso não obtivesse apoio popular. Mas seu governo fossilizado se esboroou e ele renunciou alguns meses depois, 
desaparecendo rapidamente da cena política. Sem o apoio de uma população cada vez mais cansada de barricadas, passeatas, agitações, greves gerais, atos de vandalismo e demonstrações de truculência, os protestos passaram da simples crítica e tentativa de desqualificação da autoridade estabelecida ao dogmatismo e à radicalização. E, na medida em que identificou a negação da ordem burguesa com a liquidação até mesmo dos elos mais fracos do poder estabelecido (as instituições universitárias, onde, justamente, residia sua própria força), a União Nacional dos Estudantes Franceses (Unef) entrou em crise, dividida por conflitos entre trotskistas, maoístas, stalinistas e toda a gama das esquerdas, o movimento estudantil murchou.

Com isso, a ideia de que os problemas de uma Universidade burocrática e repressiva seriam um retrato em pequena escala dos problemas gerais da sociedade capitalista progressivamente se esvaziou. Meses depois das explosivas manifestações de maio, a França já voltara à "normalidade" da vida cotidiana - ou seja, ao statu quo ante, nos planos social e econômico. A afirmação parece forte. Mas o que resultou de fato da experiência contestadora da primavera francesa de 1968 foi apenas "a oferta, aos estudantes, de cursos fantasiosos sobre o Terceiro Mundo, sobre a negritude e sobre o teatro do absurdo, enquanto (se) assegurava que as classes dirigentes continuassem se formando para governar, como sempre, nas faculdades de elite: a École Normale Supérieure e a École Nationale d'Administration"4. Por esse motivo, enquanto analistas mais progressistas afirmam que maio de 1968 de certo modo teria resgatado o que havia de emancipador das tradições cultural e revolucionária francesas, dando assim novo sentido à história, os mais conservadores classificam o período como a primavera do nada ${ }^{5}$.

Em que medida é possível fazer uma analogia dos desdobramentos da primavera francesa de 1968, quando o telefone fixo, o mimeógrafo e o megafone eram os instrumentos de comunicação e mobilização, com o outono brasileiro de 2013, em que as informações são disseminadas em tempo real e o celular e a internet dão voz a segmentos sociais que até agora não conseguiam se expressar politicamente? O movimento estudantil brasileiro terá as mesmas razões, as mesmas motivações e, principalmente, a mesma sina da dos colegas franceses de 45 anos atrás, quando havia uma angústia generalizada no sentido de uma mudança radical da sociedade, da vida tradicional e da velha moral puritana? Com seu utopismo vago, conseguirão os estudantes, os movimentos sociais e os demais grupos de protesto produzir consequências práticas, num período em que a institucionalidade da representação de interesses se revela incapaz de lidar com os conflitos entre o privado e o coletivo? Ou, no futuro próximo, será visto apenas e tão somente como uma espécie de catarse - um imenso "desrecalque coletivo".

Maio de 1968 foi produto de movimentos com núcleos duros, hierarquias definidas e lideranças centralizadoras; de organizações e grupos que ocupavam posições estratégicas na vida social e cultural francesa; de sindicatos e confederações trabalhistas, aliados a partidos de esquerda com tradição de lutas e dotados de legitimidade, que tentaram - sem sucesso - acompanhar as manifestações do movimento estudantil, para "organizá-las". Ortodoxas ou heterodoxas, a facções 
políticas formadas na ótica marxista tentaram - mas também não conseguiram tomar a direção dos protestos. Junho de 2013 é um cenário distinto, cujos atores nasceram e cresceram numa fase da vida nacional não muito bem servida de princípios éticos e marcada pelo vazio ideológico, pelo provisório e pelo imediato. Mais precisamente, junho de 2013 é um cenário em que as manifestações são coordenadas por associações e organizações relativamente desconhecidas e capazes de preservar a autonomia com relação a partidos políticos e máquinas governamentais, como é o caso do Movimento do Passe Livre; em que micro facções radicais de esquerda têm forte presença nos protestos, convictas de que a história progride pela ação de forças negativas instauradoras de um novo padrão de relações sociais; em que não há lideranças claramente definidas nem dotadas de legitimidade representativa; e em que as mobilizações - via redes sociaislevam a uma ação política menos vertical e mais horizontalizada, marcada por uma profusão de reivindicações por vezes conflitantes e excludentes; e em que muitos protagonistas são os chamados coletivos sociais e culturais, atuando com questões que vão da legalização da posse em áreas de invasão a problemas de mobilidade urbana, defesa do meio ambiente, direito das mulheres, imigrantes, grupos anarcofunk e anarcopunk, índios, GLS, negros, etc.

No desdobrar dos acontecimentos de 1968, quando a ideia de rede social ainda era impensável, o notável foi que os temas e os focos de rebelião universitária mudaram várias vezes, "sem que jamais se pudesse isolar uma palavra de ordem comum", afirma Chatelet. "Alimentada pela imagem econômica que o mundo industrial queria dar de sua eficiência gerencial e de seu progresso material, essa difusão transversal, inesperada e descontínua, desconcertou os dirigentes governamentais e políticos" - diz ele. Mesmo assim, "nenhum projeto, fruto de uma reflexão, pode ser encontrado nos desdobramentos do movimento. Aqueles líderes nos quais os manifestantes depositaram sua confiança agiram com uma espantosa sabedoria prática, evitando que surgisse o frenesi da tomada de poder. Maio de 1968 não foi um substituto da revolução, mas apenas a transformação dos costumes, fora e apesar dos poderes centrais" - conclui Chatelet ${ }^{6}$, ele próprio antigo militante da Confederação Geral do Trabalho (CGT) e um dos organizadores - ao lado de Michel Foucault e de Gilles Deleuze- do Departamento de Filosofia da Universidade de Paris VIII (Vincennes), que foi criado em resposta às reivindicações estudantis após maio de 68 .

Hoje, se é necessário ouvir a mítica, rouca e polissêmica voz das ruas, como afirmam jornalistas, intelectuais, políticos e até inquilinos temporários do Planalto, quem serão os interlocutores? As vozes das ruas são polifônicas, é certo - mas que significado atribuir a elas? O que, de fato, os manifestantes contestam? Que princípios e interesses os norteiam? O que os une e o que os divide? Que código hermenêutico será possível utilizar para interpretar e compreender o que surgiu como algo singelo - a redução de vinte centavos das tarifas de ônibuse que agora leva muitos manifestantes a afirmar que nesse pequeno valor estão embutidos não só os problemas da melhoria dos serviços públicos, como também 
a falta de canais estratégicos para a definição de um projeto de poder para o país. Nesse contexto, em que os partidos políticos não têm nem competência nem determinação e legitimidade para converter demandas pontuais em alternativas de governabilidade, qual é a diferença entre o interesse comum e o ingovernável, entre a responsabilidade compartilhada e a irresponsabilidade generalizada? Como converter os protestos em policies sem neutralizar a riqueza dos ideais neles subjacentes? E, mais importante, se algum acordo for firmado, como poderá ser implementado num momento histórico marcado pelo enfraquecimento da soberania política dos Estados, enquanto unidades auto-suficientes, e pela emergência de um mundo de interdependências, com espaços de difícil regulação e responsabilidades difusas?

$\mathrm{Na}$ democracia, o poder é uma realidade compartilhada. A ação política só é democrática se reconhecer a existência do adversário. Por isso, a política é inseparável da disposição ao compromisso, uma vez que ninguém consegue tudo o que quer, sendo, portanto, obrigado a dialogar, a transigir e a negociar. A ação política democrática está assim a serviço da vontade popular, mas a construção dessa vontade é sempre uma atividade lenta e complexa, que pressupõe compromisso e mediação, comunicação e representação. Em passagem clássica, Weber classificou a política como "um esforço tenaz e energético para atravessar grossas vigas de madeira", o que exige "paixão e senso de proporções" ${ }^{\prime}$. Em termos menos metafóricos, a representação política é um locus de participação, delegação, deliberação e decisão. Na democracia, decisão sem deliberação carece de legitimidade. Igualmente, deliberação sem decisão tende a ser ineficaz ou inócua ${ }^{8}$. A institucionalização de uma democracia representativa se dá na prática institucionalizante de sua história. Mais do que um regime de consultas, a representação democrática é um sistema que articula diversos critérios - participação cívica, qualidade da deliberação, transparência das decisões e exercício de responsabilidade. Como lembram alguns cientistas sociais de formação sistêmica, a representação democrática não é uma transposição cacofônica dos diferentes segmentos sociais, mas um esforço de síntese - uma pluralidade constitutiva, um trabalho de construção política de uma vontade coletiva.

Nesta perspectiva, a política é, também, um modo de aprendizagem sob condições de incerteza e de avaliação de riscos e contingências. Mais precisamente, a política ajuda a sociedade a adquirir uma certa distância a respeito de si mesma. É, assim, uma forma de reflexividade que abre para a sociedade a possibilidade de examinar criticamente suas práticas e seus sistemas de representação de interesses. No espaço público da palavra e da ação, o que está em primeiro plano são processos e estratégias comunicativas que contribuem para a formação e transformação de opiniões, interesses e identidades dos cidadãos. O objetivo desses processos e dessas estratégias não é satisfazer interesses particulares, mas elaborar coletivamente interpretações comuns da convivência - inclusive quando determinadas segmentos sociais apresentam reivindicações inteiramente formuladas à margem da realidade social e econômica. 
Essas considerações ajudam a compreender as manifestações de protesto no Brasil, que ocorreram num período marcado por oscilações no desempenho da economia e forte dinamismo social. Trata-se de um momento histórico em que, depois da ascensão ao mercado consumidor de milhões de brasileiros que estavam na chamada classe D, entre 2006 e 2010, a acentuada redução no ritmo do crescimento econômico registrada nos anos seguintes disseminou nesse mesmo contingente o temor do desemprego generalizado - e, por tabela, o "medo de perder o que foi obtido", o receio "de uma queda livre, sem rede de proteção, dos trapézios sociais alcançados" - como observou Wanderley Guilherme dos Santos. Em períodos históricos como esses, diz ele, "rápidos deslocamentos ascendentes desenraizam as pessoas da matriz societária original, provocando crises de identidade e desorientação quanto a valores, estando por serem substituídos os anteriores, desaprendidos. Max Weber apontou a reserva de ebulição aí depositada, tanto quanto nas crises de despenhadeiro, quando enormes contingentes de trabalhadores são despejados na escala social com destino à miséria e à desesperança. E, ambos, períodos de extensa anomia social, insegurança quanto a rumos e subversão de critérios de avaliação e escolha social".

Em outra linha de argumentação, mas também levando em conta os dois momentos acima mencionados, o de crescimento com inclusão social e o da queda do nível de atividade econômica com a possibilidade desemprego e mobilidade social descendente, Gabriel Cohn lembra que indignação moral, protestos e recusa coletiva à obediência são virtudes cívicas necessárias, mas não suficientes, para produzir a transição das expressões dos mais variados segmentos sociais para um plano macro ${ }^{10}$. Assim, quando os partidos não conseguem atuar como instâncias intermediárias, convertendo demandas sociais em alternativas concretas de governabilidade capazes de melhorar a qualidade do serviço público, assegurar a continuidade do emprego e garantir conquistas, as ruas acabam funcionando como válvulas de escape. Elas expressam um mal estar generalizado. Chamam atenção para um estado insuportável de coisas. Denunciam a crise de representação e reivindicam canais não viciados para se exprimir. Atuam como mecanismos de estabilização da democracia, ajudando a aumentar os níveis de responsabilidade e competência que os cidadãos exigem dos dirigentes governamentais, por um lado, e a restabelecer a credibilidade e legitimidade do sistema partidário, por outro.

Em momentos históricos como o vivenciado pelo Brasil na altura de junho de 2013, é absolutamente natural, compreensível e legítimo que os mais variados setores da sociedade saiam às ruas, às avenidas e às praças para reafirmar o direito de se reunir e de expressar demandas que agremiações partidárias embotadas em sua sensibilidade, oxidadas pela rigidez de suas burocracias e minadas em sua autoridade pelo clientelismo, pelo fisiologismo e pela corrupção não conseguem 
captar. As manifestações de protesto tendem assim a oxigenar e a revitalizar os mecanismos representativos, abrindo caminho para a substituição de agremiações ideológica e moralmente corrompidas por uma organização partidária mais consistente e legítima e aprofundando, com isso, o processo democrático.

Protestos e manifestações de rua, contudo, também podem levar à violência e atos inconsequentes, principalmente quando provocados ou protagonizados por minorias proto fascistas, neonazistas, anarquistas e totalitárias. Nesse sentido, como distinguir ódio destrutivo e indignação justa na voz rouca das ruas? De que modo evitar a indignação improdutiva, por meio de uma contumaz desqualificação das instituições, da intimidação ou ameaça e do vandalismo? Como afastar o risco das aventuras populistas, que inviabilizam a construção de um interesse geral com seus atributos de equilíbrio e responsabilidade? O risco, assim, é confundir as coisas, sobrepondo-se a voz das ruas à representação democrática. É esquecer que o fascínio pelas redes sociais, a fé na espontaneidade popular, a sedução pela democracia direta, o encanto pela autogestão, a crença no povo como uma unidade metafísica ou substância incorruptível da nação e a subsequente desintermediação política daí advinda podem levar não a uma revolução, mas à ausência de sentido de responsabilidade - ou seja, à demagogia, à anarquia e à truculência.

Talvez esteja aí uma das principais diferenças entre maio de 1968 e junho de 2013. Nas ruas francesas, a preocupação era denunciar e subverter com base na tensão inexorável entre uma direita e uma esquerda minimamente institucionalizadas. Os manifestantes da primavera parisiense de 45 anos atrás, lembra Hannah Arendt, teriam encontrado aquilo que o século 18 chamou de felicidade pública: quando o homem toma parte da vida pública, ele abre para si mesmo um a dimensão da experiência humana que, de outra forma, ficarlhe ia fechada e que, de certo modo, constitui parte da felicidade completa ${ }^{11}$. Já nas ruas brasileiras no outono de 2013, em cujo âmbito as manifestações de indignação e protesto são 'multiclassistas', a tensão entre direita e esquerda parece menos presente. $\mathrm{O}$ que se tem são redes sociais cuja expansão vem aumentando progressivamente o descompasso entre a dinâmica do sistema partidário e as demandas por uma cidadania maior e mais efetiva. O que se tem, igualmente, são gestos críticos e protestos expressivos de associações, organizações e movimentos sociais - uma espécie de espetacularização da vida pública, que valoriza o que choca e produz fortes imagens midiáticas, por meio de cartazes simples, mas irônicos e corrosivos. Acima de tudo, são insurreições expressivas, em que os vencedores saem vivificados e políticos e governantes acabam desqualificados e desmoralizados; não insurreições desestabilizadoras, de caráter revolucionário.

Dito de outro modo, manifestações de rua são iniciativas importantes para recuperar a representatividade de uma democracia destituída de alternativas concretas de governabilidade, mas não para substituir as instituições políticas e jurídicas. "Não há nada que recorde a velha aspiração de assaltar o poder" 
- diz o respeitado filósofo político basco Daniel Innerarity ${ }^{12}$. A proposta mais ambiciosa dos manifestantes responsáveis é a de beneficiar-se dos interstícios ou brechas do Estado para protestar e gritar suas demandas diversificadas. O resto é a irracionalidade das turbas. "A indignação moral e o insurreicionismo expressivo não devem ser entendidos como a ante-sala de mudanças revolucionárias", afirma Innerarity - depois de lembrar que, além de não serem excludentes, as ruas não são necessariamente melhores do que as instituições. Numa vida pública sem o império da lei e sem representação minimamente estruturada, onde cada um se junta com qualquer um que lhe parece semelhante, as ruas - sempre voláteispodem ser piores. E até reacionárias.

\section{NOTAS}

1 Cf. Antonio Negri e Giuseppe Cocco, Reconquista da vida, entrevista concedida ao jornal O Globo, edição de 31 de maio de 2008.

2 Cf. François Chatelet, Um desrecalque coletivo, in O Estado de S. Paulo, Suplemento Especial, edição de 7 de maio de 1978. Cinco anos depois, Olgária Matos retomaria a discussão, com base nos mesmos panfletos, afirmando que "o maio francês significou a primeira crítica radical à 'miserabilidade moderna': crítica da miséria psíquica, urbana, sexual, ideológica. Evidenciou a miséria de uma civilização, a capitalista pós-keynesiana, que se vangloriava de sua decrescente miséria econômica. A revolução dos jovens foi a consciência manifesta de miséria dorée". Cf. Maio de 68, o poder em questão, in Folha de S. Paulo, Folhetim, edição de 2 de maio de 1982.

3 Cf. Hannah Arendt, Reflexões sobre Política e Revolução, entrevista concedida a Adelbert Reif e incluído como anexo em Crises da República, São Paulo, Perspectiva, 1973. "Se os estudantes triunfarem na destruição das universidades, terão destruído sua própria base de operações (...). Se destruírem as universidades, não existirá mais nada parecido com elas; consequentemente, tampouco haverá rebelião contra a sociedade (...). Isto está relacionado com a radicalização violenta. Por este caminho o movimento estudantil poderia não somente fracassar em conseguir o que exige, mas também ser destruído" - afirmou ela (p. 179-180).

4 Cf. Carlos Fuentes, Em 68: Paris, Praga e México, Rio de Janeiro, Rocco, 2005, p.14; e Alain Touraine, Como entender as barricadas nas ruas de Paris, in Jornal da Tarde, edição de 6 de maio de 1978.

5 Cf. Roque Spencer Maciel de Barros, A primavera do nada, in O Estado de S. Paulo, Suplemento Especial, edição de 7 de maio de 1978.

6 Cf. François Chatelet, op.cit.

7 Cf. Max Weber, A política como vocação, in Ciência e Política: duas vocações, São Paulo, Cultrix, 1970, p. 123.

8 Cf. Daniel Innerarity, La política después de la indignación, in Claves de Razón Practica, Madrid, $2011, n^{\circ} 218$.

9 Cf. Wanderley Guilherme dos Santos, Anomia niilista, in Valor Econômico, edição de 26 de junho de 2013, e "Existe um contingente de insatisfação niilista no país", entrevista concedida à revista Conjuntura Econômica, Rio de Janeiro, vol. 67, nº8.

10 Cf. Gabriel Cohn, entrevista ao jornal Valor Econômico, edição de 21 de junho de 2013 ("Para Cohn, partidos permanecem essenciais").

11 Cf. Hannah Arendt, Entre o Passado e o Futuro, São Paulo, Perspectiva, 1972.

12 Cf. Daniel Innerarity, op. cit. 


\section{Resumo}

O presente artigo tem como objetivo realizar uma breve análise comparativa entre dois fenômenos históricos: o Maio de 1968, na França, onde uma greve geral restou por desencadear manifestações de cunho revolucionário, e o Junho de 2013, no Brasil, onde uma série de manifestações, inicialmente em protesto contra o aumento de preços do transporte público, restou por tomar proporções inesperadas. Possui como premissa, portanto, a identificação de suas divergências e simetrias.

Palavras-chave: Manifestações Populares. Maio de 1968. Junho de 2013. 


\title{
FROM MAY 1968 TO JUNE 2013
}

\begin{abstract}
This article aims to conduct a brief comparative analysis between two historical phenomena: May 1968 in France, where a general strike left to trigger revolutionary nature of demonstrations, and June 2013, in Brazil, where a series of demonstrations initially in protest against the increase in public transport prices, left to take unexpected proportions. It has as a premise, therefore, to identify their differences and symmetries.
\end{abstract}

Keywords: Popular Demonstrations. May 1968. June 2013.

Recebido em 24 de agosto de 2017 Aprovado em 30 de maio de 2018 